\title{
OBSESSIVE COMPULSIVE DISORDER AND DISSOCIATION - COMPARISON WITH HEALTHY CONTROLS
}

\author{
Jan Prasko ${ }^{\mathrm{a}, \mathrm{b}, \mathrm{c}, \mathrm{d}}$, Michal Raszka ${ }^{\mathrm{c}, \mathrm{d}}$, Tomas Diveky ${ }^{\mathrm{a}, \mathrm{b}}$, Ales Grambala ${ }^{\mathrm{a}, \mathrm{b}}$, Dana Kamaradova ${ }^{\mathrm{a}, \mathrm{b}}$, \\ Jana Koprivova ${ }^{\mathrm{c}, \mathrm{d}}$, Klara Latalova ${ }^{\mathrm{a}, \mathrm{b}}$, Petr Pastucha ${ }^{\mathrm{b}, \mathrm{e}}$, Zuzana Sigmundova ${ }^{\mathrm{a}, \mathrm{b}}$ \\ a Department of Psychiatry, Faculty of Medicine and Dentistry, University Palacky and University Hospital, I. P. Pavlova 6, \\ Olomouc, Czech Republic \\ ${ }^{b}$ Faculty of Medicine and Dentistry, University Palacky Olomouc \\ c Prague Psychiatric Centre \\ ${ }^{d}$ Centre of Neuropsychiatric Studies \\ e Outpatient Department of Psychiatry, Valasske Mezirici \\ E-mail: prasko@fnol.cz
}

Received: January 24, 2009; Accepted: June 17, 2010

Key words: Obsessive/Compulsive/Disorder/Dissociation/Anxiety/Depression

The aim of our study is to examine if the dissociation can influence the intensity of psychopathology in patients suffering from obsessive compulsive disorder and to compare the levels of dissociation in the groups of the patients and healthy subjects.

Method. Fifty five patients suffering from obsessive compulsive disorder and 123 healthy controls were included into the study. The patients were psychiatrically assessed. The diagnosis was made using ICD-10 research criteria confirmed with structured interview MINI. The subjective intensity of anxiety and depressive symptoms was evaluated using Beck Anxiety Inventory and Beck Depression Inventory. The intensity of obsessions and compulsions was evaluated using Yale Brown Obsessive Compulsive Scale. All participants were assessed with the Dissociative Experiences Scale (DES).

Results. Level of the psychological dissociation assessed with the DES was correlated with the severity of subjective anxiety $(p<0.0001)$, depression $(p<0.0001)$, and with the severity of obsessive-compulsive symptoms $(p<0.005)$. Patients have significantly lower mean score on the DES than healthy controls $(p<0.0001)$.

Conclusion. Our results suggest that the level of psychological dissociation in OCD patients is lower than in healthy controls, and is associated with the severity of anxiety, depression and obsessive compulsive symptoms.

\section{INTRODUCTION}

Obsessive compulsive disorder (OCD) is a severe and mostly disabling condition with a prevalence rate of 1.9-3.2 \% (ref. ${ }^{1}$ ). More than half of obsessive compulsive disorder patients have a chronic and/or recurrent form of the disorder, accounting for much of the individual and societal cost associated with the illness ${ }^{2}$. Some reports have pointed at the possible association between obsessive-compulsive disorder and dissociation. More severe OCD symptoms were proven in patients with a higher degree of dissociation ${ }^{3}$. A case history of an OCD patient who developed dissociative symptoms during exposure treatment had initiated further research ${ }^{4}$. The study suggested that dissociative experiences may have prevented desensitization in this patient during exposure therapy. In the study conducted by Goff et al. ${ }^{3}$ patients

\section{ABBREVIATIONS}

BAI - Beck Anxiety Inventory

BDI - Beck Depression Inventory

DES - Dissociative Experiences Scale

ns - non significant

Y-BOCS - Yale Brown Obsessive Compulsive Scale who scored 20 or higher on the Dissociative Experience Scale - $\left(\mathrm{DES}^{5}\right)$ had significantly more severe OCD and depressive symptoms than OCD patients with the DES score less than 20 . Raszka et al. ${ }^{6}$ suggested that the level of psychological dissociation is associated with the severity of anxiety symptoms rather than with obsessive compulsive symptoms. Dissociation might be a negative predictor of treatment outcome in cognitive-behavioural therapy for patients with anxiety disorders ${ }^{7}$. More severe OCD symptoms after cognitive-behavior therapy were associated with higher DES scores at baseline, and treatment nonresponders had significantly higher baseline DES scores compared to responders ${ }^{8}$. High level of dissociation can be one of the reasons for treatment resistance in patients suffering from OCD 9 .

The aim of our study was to examine if the dissociation is connected with the subjective severity of anxiety, depressive and obsessive compulsive symptoms in patients suffering from obsessive compulsive disorder and if the intensity of dissociation differs from the healthy controls. We hypothesized that obsessive compulsive disorder patients have suffered from higher levels of dissociation, than healthy controls, and the level of dissociation will be correlated with the subjectively experienced severity of anxiety, depression, and obsessive compulsive symptoms. 


\section{METHOD}

Fifty five outpatients with obsessive compulsive disorder and 123 healthy controls were included into the study.

Inclusion criteria were:

a) ICD-10 research criteria for obsessive compulsive disorder

b) Age 17-70 years

c) Male and female

\section{Exclusion criteria:}

a) Depressive disorder (ICD-10 criteria for depressive disorder)

b) Organic psychiatric disorder

c) Psychotic disorder in history

d) Posttraumatic stress disorder

e) Borderline personality disorder

f) Dissociative disorder

g) Substance dependence

h) Serious somatic disease

Assessment. Anxiety symptoms were evaluated with a self-administered 21-item scale - the Beck Anxiety Inventory $\left(\mathrm{BAI}^{10}\right)$. The level of depressive symptoms was rated using the self-administered 21-item Beck Depression Inventory-II (BDI-II $\left.{ }^{11}\right)$. Severity of obsessions and compulsions was assessed by Y-BOCS (Yale-Brown Obsessive Compulsive Scale ${ }^{12}$ ). Psychological dissociative symptoms were examined using the Dissociative Experiences Scale $\left(\mathrm{DES}^{13}\right)$. The DES is a self-administered 28-item inventory of psychological dissociation, where participants are asked to indicate on a visual analog scale how often they experience the dissociative symptoms (in percentage of time). The Czech version of the scale is comparable to the original version in terms of its test-retest reliability, validity and factor structure ${ }^{14}$. Investigation was carried out in accordance with the latest version of the Declaration of Helsinki and ICH-GCP guidelines (International Conference on Harmonization, Good Clinical Practice). The local ethics committee approved the study and informal consent.

Participants. 55 patients with obsessive compulsive disorder between 17 and 69 years of age (58.2\% females; mean age $31.20 \pm 9.09$ years) from the Outpatient department of Prague Psychiatric centre, the Outpatient department Valasske Mezirici, and Outpatient department of Psychiatric clinic of the University Hospital Olomouc, were recruited for this study. All patients were outpatients. All patients used psychotropic medication, mostly SSRIs in obvious therapeutic dosages. One hundred twenty three healthy controls ( $74.8 \%$ females) without any lifetime Axis I diagnosis were recruited through local advertisement. The controls were aged between 17 and 50 years (mean age $31.89 \pm 9.62$ years). All participants signed an informed consent before entering the study. The mean scores in DES, BAI, BDI and Y-BOCS are described in Table 1.
Data analysis. Patient's demographic and baseline clinical characteristics were analysed using column statistics. Normal distribution of the demographic and clinical variables was determined by the Shapiro-Wilk W test, with exception of DES. Differences between patients with obsessive compulsive disorder and healthy controls were analyzed using t-tests for independent groups and the Mann-Whitney test. The relationships between variables with normal distribution (BDI, BAI, Y-BOCS) were calculated using Pearson correlation analysis, while Spearman correlation was used for variables with non-normal distribution of DES. Linear regression with the DES score as independent variable and age, BDI, BAI, Y-BOCS scores as dependent variables were carried out to identify the principal clinical variables which influence the severity of dissociative symptoms in obsessive compulsive disorder patients. The level of significance was set at $p<0.05$. All analyses were conducted using STATISTICA 7.0 software.

\section{RESULTS}

Sociodemographic and clinical variables and the frequency of dissociative experiences between obsessive compulsive patients and healthy controls

Comparisons of the sociodemographic and clinical characteristics of obsessive compulsive disorder patients and controls are shown in Table 1. No significant age and education differences were found between the groups. There is statistically significant higher male/female ratio in OCD patients than in healthy controls (Fisher's exact test: $p$ < 0.05). Patients receive lower mean score of DES than healthy controls (means: $13.11 \pm 13.75$ respective $22.54 \pm 20.77$ Kruskal Wallis test: $\mathrm{p}<0.0001$ ); and they score less frequent higher than 20 on the DES scale $(23.64 \%$ of OCD patients versus $42.2 \%$ of healthy volunteers, Fisher's exact test; $p<0.05$ ).

\section{Correlation analyses and linear regressions in obsessive compulsive group}

Relatively strong associations between level of anxiety, depression, obsessive compulsive symptoms and DES scores were found in correlation analyses. Spearman correlations are presented in Table 2.

Psychological dissociation assessed with the DES was associated with the severity of anxiety symptoms (DES versus BAI: linear regression: $p<0.0005$ ), depressive symptoms (linear regression: $\mathrm{p}<0.005$ ) and obsessive compulsive symptoms (linear regression: $\mathrm{p}<0.05$ ) but not with the age (linear regression: ns) (Table 3, Fig. 2).

\section{Male/female differences in rating scales}

There are differences between men and women suffering from OCD in mean scores of DES (Mann Whitney test: $p<0.05$ ), BAI (unpaired t test: $p<0.01$ ), BDI (unpaired t test: $\mathrm{p}<0.05$ ) and Y-BOCS (unpaired test: $\mathrm{p}<0.05)$. There is no difference between DES in men and women in group of controls (Mann Whitney test: ns). There are not statistically significant differences between 
Table 1. Comparison of demographic and clinical characteristics of subjects with obsessive compulsive disorder and healthy subjects.

\begin{tabular}{|l|c|c|c|}
\hline & $\begin{array}{c}\text { Obsessive compulsive } \\
\text { disorder }(\mathrm{n}=55)\end{array}$ & Healthy controls $(\mathrm{n}=123)$ & $\begin{array}{c}\text { Statistical test: } \\
\text { significance }\end{array}$ \\
\hline Age (years) & $31.20 \pm 9.09$ & $31.89 \pm 9.62$ & Kruskal Wallis test: $\mathrm{ns}$ \\
\hline Gender: male / female & $23 / 32$ & $31 / 92$ & Fisher's exact test: $\mathrm{p}<0.05$ \\
\hline $\begin{array}{l}\text { Education (basic / second- } \\
\text { ary / university) }\end{array}$ & $0 / 38 / 17$ & $4 / 72 / 47$ & chi-square: $\mathrm{ns.}$ \\
\hline BAI & $15.2 \pm 11.86$ & - & - \\
\hline BDI & $12.5 \pm 9.98$ & - & - \\
\hline Y-BOCS & $20.89 \pm 10.6$ & $22.54 \pm 20.77$ & $\begin{array}{c}\text { Kruskal Wallis test: } \\
\mathrm{p}<0,0001\end{array}$ \\
\hline DES (average) & $13.11 \pm 13.75$ & $52(42.3 \%)$ & Fisher's exact test: $\mathrm{p}<0,05$ \\
\hline DES higher than 20 & $13(23.64 \%)$ & $28(22,8 \%)$ & Fisher's exact test: $\mathrm{ns}$ \\
\hline DES higher than 30 & $7(14.58 \%)$ & & - \\
\hline
\end{tabular}

Results are reported as account or mean \pm SD.

Abbreviations:

DES - Dissociative Experiences Scale; BAI - Beck Anxiety Inventory ; BDI - Beck Depression Inventory; Y-BOCS

- Yale Brown Obsessive Compulsive Scale; ns - non significant,

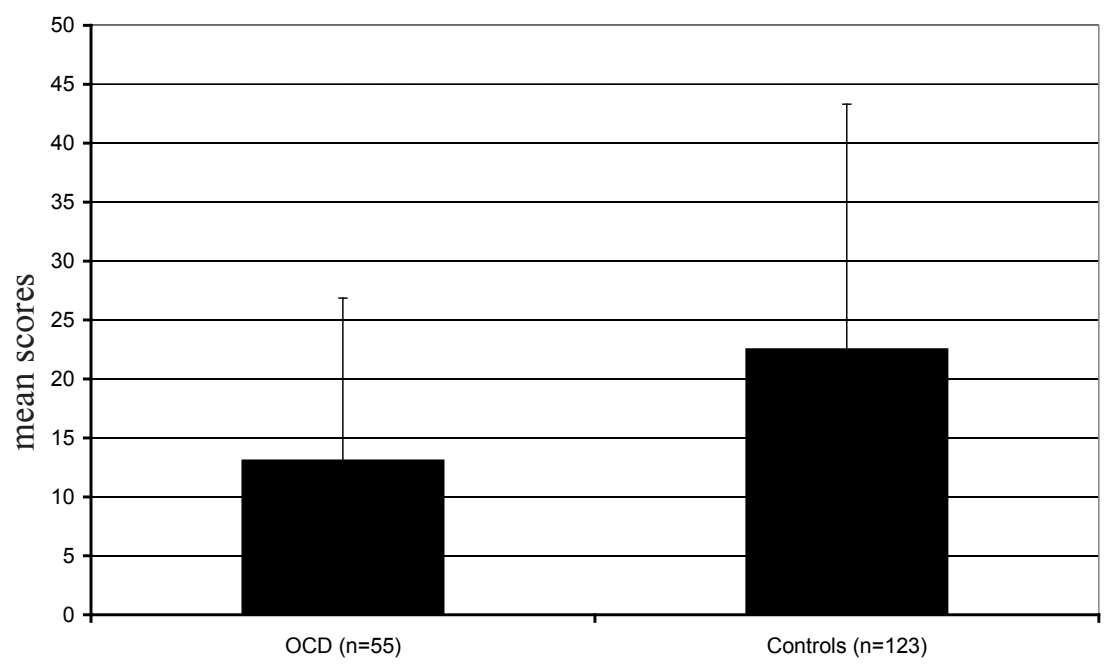

Kruskal Wallis test: $\mathrm{p}<0.0001$

Fig. 1. Comparison of mean DES between patients and controls.

DES scores of females between OCD and controls (Mann Whitney test: ns) but there was difference between DES scores of males between groups (Mann Whitney test: $p$ $<0.01$ ) (Table 4).

\section{DISCUSSION}

Our first hypothesis (obsessive compulsive disorder patients have suffered from higher levels of dissociation, than healthy controls) has not been confirmed. In reality, the results are opposite to our hypothesis. The mean score of psychological dissociation measured with DES in patient suffering from obsessive compulsive disorder is 
Table 2. Spearman's correlation coefficients between DES versus age, BAI, BDI, Y-BOCS, in obsessive compulsive disorder group.

\begin{tabular}{|c|c|c|c|c|}
\hline & Age & BAI & BDI & Y-BOCS \\
\hline Spearman $\mathrm{r}$ & 0.09147 & 0.5425 & 0.5497 & 0.3798 \\
\hline $\mathrm{p}$ value & $\mathrm{ns}$ & $\mathrm{p}<0.0001$ & $\mathrm{p}<0.0001$ & $\mathrm{p}<0.005$ \\
\hline
\end{tabular}

Table 3. Linear regression of DES versus age, BAI, BDI, Y-BOCS in obsessive compulsive disorder group.

\begin{tabular}{|c|c|c|c|c|}
\hline & Age & BAI & BDI & Y-BOCS \\
\hline $\mathrm{r}^{2}$ & 0.002221 & 0.2327 & 0.1478 & 0.07706 \\
\hline $\mathrm{F}$ & 0.1180 & 15.77 & 9.022 & 4.425 \\
\hline $\mathrm{DFd}$ & 53 & 53 & 53 & 53 \\
\hline $\mathrm{p}$ value & 0,7326 & $\mathrm{p}<0.0005$ & $\mathrm{p}<0.005$ & $\mathrm{p}<0.05$ \\
\hline
\end{tabular}

Table 4. Male/female differences in means of rating scales.

\begin{tabular}{|l|c|c|c|c|c|}
\hline & $\begin{array}{c}\text { DES in OCD pa- } \\
\text { tients (23 males } \\
\text { and 32 females) }\end{array}$ & $\begin{array}{c}\text { DES in controls } \\
(31 \text { males and 92 } \\
\text { females })\end{array}$ & $\begin{array}{c}\text { BAI in OCD } \\
(22 \text { males and 31 } \\
\text { females })\end{array}$ & $\begin{array}{c}\text { BDI in OCD } \\
(22 \text { males and 31 } \\
\text { females })\end{array}$ & $\begin{array}{c}\text { Y-BOCS in OCD } \\
(23 \text { males and 31 } \\
\text { females })\end{array}$ \\
\hline Males & $9.264 \pm 10.58$ & $26.23 \pm 24.32$ & $10.55 \pm 9.25$ & $8.86 \pm 7.30$ & $17.65 \pm 10.66$ \\
\hline Females & $15.88 \pm 15.20$ & $21.30 \pm 19.42$ & $18.90 \pm 12.40$ & $15.48 \pm 10.71$ & $23.77 \pm 9.73$ \\
\hline $\mathrm{t}$ & & 2.674 & 2.512 & 2.195 \\
\hline $\mathrm{df}$ & $\mathrm{p}$ & 51 & 51 & 52 \\
\hline $\mathrm{p}$ value & $\begin{array}{c}\text { Mann Whitney: } \\
\mathrm{p}<0.05\end{array}$ & $\begin{array}{c}\text { Mann Whitney: } \\
\text { ns }\end{array}$ & $\begin{array}{c}\text { unpaired } \mathrm{t} \text { test: } \\
\mathrm{p}<0.01\end{array}$ & $\begin{array}{c}\text { unpaired } \mathrm{t} \text { test: } \\
\mathrm{p}<0.05\end{array}$ & $\begin{array}{c}\text { unpaired } \mathrm{t} \text { test: } \\
\mathrm{p}<0.05\end{array}$ \\
\hline
\end{tabular}

statistically significantly lower than mean score in healthy controls. Higher psychological dissociative symptoms have been experiencing less frequently in OCD patients than in healthy controls. How to explain these results is unclear. The old Freudian theory speculated that obsessive compulsive symptomatology is opposite to dissociate symptomatology, but there are no evidence based results confirmed this speculation. Our results could confirm this speculation. On the other side, there can be problem of using measurement instrument DES in OCD population. DES is highly significantly correlated with BDI and BDI and can be influenced largerly by anxiety and depressive symptoms in anxiety disorders and depression ${ }^{14}$. If the anxiety and depression symptoms in OCD are not so high, what was seen in our population, we cannot see so high level of dissociation measured with DES. The question whether dissociative states are components of anxiety or can be understood as an independent construct is now discussed ${ }^{6,15}$.

Our second hypothesis (the level of dissociation will be correlated with the subjectively experienced severity of anxiety, depression, and obsessive compulsive symptoms)

\section{Data Table-5}

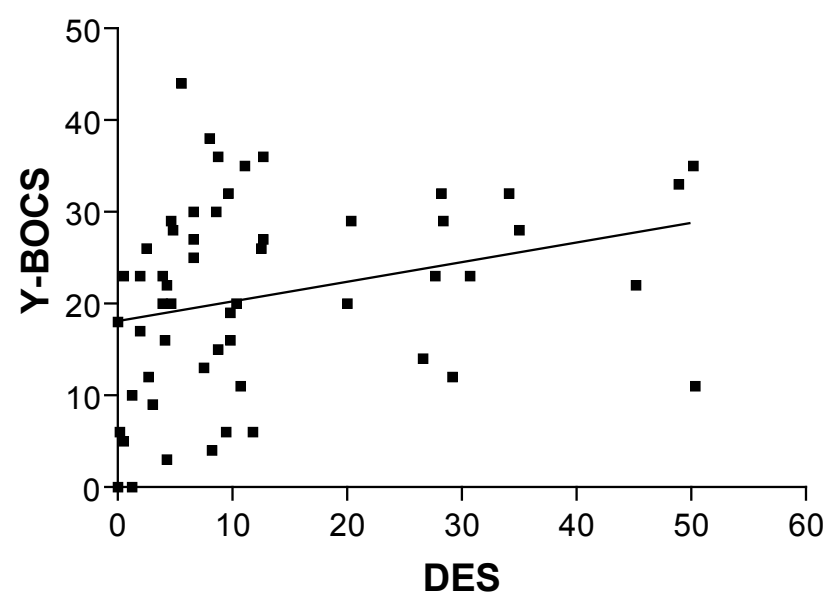

Fig. 2. Linear regression of DES and Y-BOCS. 
has been fully confirmed. The level of psychological dissociation of our patients highly correlated with the severity of subjective anxiety, depression and also with severity of obsessive compulsive symptomatology.

The patients with OCD reached levels of psychological dissociation assessed by the DES comparable to those found by Rufer et al. ${ }^{16}$. There was a positive correlation between psychological dissociation and depressive symptoms. This is in agreement with previous studies of $\mathrm{OCD}^{3,16}$. Fontenelle et al. ${ }^{17}$ revealed that the severity of dissociation measured by DES predicted the level of OCD symptoms in Y-BOCS. We obtained the same results in presented study.

Our study has substantial limitations that should be considered. There have been using self-report questionnaires for assessment the scores of depression, anxiety, and dissociation. Future research should corroborate these questionnaires with clinician-rated instruments. A further limitation of our study is in relatively small sample size, which made impossible the evaluation of different subgroups of obsessive compulsive disorder. There was also been statistically significant difference between patients group and controls in male/female ratio which could influence the results. In reality there was not statistically significant difference between DES scores of females between OCD and controls but there was difference between DES scores of males between groups. In the case there are more female's cases in OCD group, comparable with the amount of females in control group, it is possible that the difference of DES between OCD and controls disappears. Nevertheless the differences in DES between males of OCD group and controls sustain. There was another limitation which we must mention: the most of the patient used psychotropic medication, which can influence (decrease) the level of dissociation. Further study with drug-free patient could be done to overcome this issue.

- In conclusion, our results suggest: lower level of psychological dissociation in OCD in comparison with the healthy controls;

- this difference is mainly due a low level of dissociation in males with OCD;

- close relation of dissociative states with the level of anxiety, depressive and obsessive compulsive symptomatology in obsessive compulsive disorder

We need further research to explore the role of dissociation in different types of OCD and to differentiate influence of dissociation on one side from the anxiety and depressive symptoms on the other side.

\section{REFERENCES}

1. Karno M, Golding JM, Sorenson SB. The epidemiology of obsessive-compulsive disorder in five US-comunities. Arch Gen Psychiatry 1988; 45:1094-1099.

2. Kaplan A, Hollander E. A review of pharmacologic treatments for obsessive - compulsive disorder. Psychiatric Services 2003; 54(8):1111-1118.

3. Goff DC, Olin JA, Jenike MA, Baer L, Buttolph ML. Dissociative symptoms in patients with obsessive-compulsive disorder. J Nerv Ment Dis 1992; 180(5):332-37.

4. Bartlett AE and Drummond LM. Hysterical conversion and dissociation arising as a complication of behavioural psychotherapy treatment of obsessive-compulsive neurosis. $\mathrm{Br} \mathrm{J}$ Med Psychol 1990; 63(2):109-115.

5. Bernstein EM and Putnam FW. Development, reliability, and validity of a dissociation scale. J Nerv Ment Dis 1986; 174(12):727-35.

6. Raszka M, Praško J, Kopřivová J, Novák T, Adamcová K. Psychological dissociation in obsessive-compulsive disorder is associated with anxiety level but not with severity of obsessive-compulsive symptoms. Neuroendocrinol Lett 2009; 30(5):624-628.

7. Spitzer C, Barnow S, Freyberger HJ, Grabe HJ (2007): Dissociation predicts symptom-related treatment outcome in short-term inpatient psychotherapy. Aus N Z J Psychiatry 2007; 41:682-687.

8. Rufer M, Fricke S, Held D, Cremer J, Hand I. Dissociation and symptom dimensions of obsessive-compulsive disorder : A replication study. Eur Arch Psychiatry Clin Neurosci 2006; 256(3):14650.

9. Praško J, Raszka M, Adamcová K, Grambal A, Kopřivová J, Kudrnovská H, Látalová K, Vyskočilová J. Predicting the therapeutic response to cognitive behavioural therapy in patients with pharmacoresistant obsessive-compulsive disorder. Neuroendocrinol Lett 2009; 30(5):615-623.

10. Beck AT, Epstein N, Brown G, Steer RA. An Inventory for Measuring Clinical Anxiety: Psychometric Properties. J Consult Clin Psychol 1988; 56(6):893-97.

11. Beck AT, Steer RA, Ball R, Ranieri W. Comparison of Beck Depression Inventories -IA and -II in psychiatric outpatients. J Pers Assess 1996; 67(3):588-97.

12. Goodman WK, Rasmussen SA, Price LH et al. (1986). Yale-Brown Obsessive-Compulsive Scale (Y-BOCS). New Haven, CT, Yale University, Department of Psychiatry.

13. Carlson EB, Putnam FW. An update on the Dissociative Experience Scale: An update on the Dissociative. Dissociation 1993; 6:16-27.

14. Ptacek R, Bob P, Paclt I, Pavlat J, Jasova D, Zvolsky P et al. Psychobiology of dissociation and its clinical assessment. Neuro Endocrinol Lett 2007; 28: 191-198.

15. Hunter EC, Sierra M, David AS. The epidemiology of depersonalisation and derealisation. A systematic review. Soc Psychiatry Psychiatr Epidemiol 2004; 39:9-18.

16. Rufer M, Held D, Cremer J et al. Dissociation as a predictor of cognitive behavior therapy outcome in patients with obsessivecompulsive disorder. Psychother Psychosom 2006; 75(1):40-46.

17. Fontenelle LF, Dominigues AM, Souza WS, Mendlowicz MV, de Menezes GB, Figueira IL et al. History of trauma and dissociative symptoms among patients with obsessive-compulsive disorder and social anxiety disorder. Psychiatr Q 2007; 78:241-250.

\section{AKNOWLEDGEMENT}

This paper was supported by the research grant IGA MZ CR NS 9323/3. 